\title{
DETERMINAÇÃO DA FRAGILIDADE AMBIENTAL DE BACIAS HIDROGRÁFICAS
}

\author{
Geula Graciela Gomes Gonçalves ${ }^{1}$, Omar Daniel $^{2}$, Éder Comunello ${ }^{3}$, Antonio Carlos Tadeu Vitorino ${ }^{4}$, \\ Fabiane Kazue Arai $^{5}$ \\ ${ }^{1}$ Bióloga, M.Sc., UFGD, Dourados, MS, Brasil - gracielagomes2003@yahoo.com.br \\ ${ }^{2}$ Eng. Florestal, Dr., Faculdade de Ciências Agrárias, UFGD, Dourados, MS, Brasil - omar.daniel@pq.cnpq.br \\ ${ }^{3}$ Eng. Agrônomo, M.Sc., EMBRAPA Agropecuária Oeste - eder@cpao.embrapa.br \\ ${ }^{4}$ Eng. Agrônomo, Dr., Faculdade de Ciências Agrárias, UFGD, Dourados, MS, Brasil - antoniovitorino@ufgd.edu.br \\ ${ }^{5}$ Eng ${ }^{a}$ Agrônoma, Doutoranda em Agronomia, UFGD, Dourados, MS, Brasil - fabiane.kazue.arai@ gmail.com \\ Recebido para publicação: 14/09/2010 - Aceito para publicação: 04/08/2011
}

\begin{abstract}
O objetivo deste estudo foi adaptar a proposta metodológica de Ross (1994) para novos procedimentos de determinação da fragilidade ambiental. Para o trabalho de geoprocessamento, foi utilizado o Sistema de Informação Geográfica (SIG) SPRING, tendo como bases cartográficas imagens LANDSAT/TM 5. Foram gerados os mapas de fragilidade potencial e emergente. O primeiro foi elaborado por meio da sobreposição dos planos de informação de declividade, erodibilidade, erosividade e geologia. Para a geração do mapa de fragilidade emergente, efetuou-se a sobreposição do mapa de fragilidade potencial ao mapa de uso da terra. Os resultados demonstraram que: a adaptação da base metodológica com a integração dos fatores de análise declividade, erodibilidade, erosividade e geologia promoveram diferenciação significativa na elaboração do mapa final de fragilidade ambiental; a utilização da classificação contínua por meio da média ponderada permitiu uma análise da fragilidade ambiental condizente com a escala de trabalho utilizada; os SIG, por meio do SPRING e da álgebra de mapas, demonstraram eficácia na análise da fragilidade ambiental, atestando a possibilidade de aplicação da metodologia em estudos de planejamento ambiental em bacias hidrográficas.

Palavras-chave: Vulnerabilidade; sistema de informação geográfica (SIG); uso da terra.
\end{abstract}

Resumo

\begin{abstract}
Determination of environmental fragility of watersheds. The aim of this study was to promote the adaptation of new procedures for determining the environmental fragility of watersheds, based on the method proposed by Ross (1994), taking as a case study the Dourados river watershed. For the geoprocessing was used the Geographic Information System (GIS) and LANDSAT/TM 5 images as a cartographic base. The maps of potential and emerging fragility were generated. The first was prepared by the overlapping of layers of slope, erosivity, erodibility and geology, and the emerging fragility map was obtained by cross referencing the map of potential fragility with the map of soil use. Results showed that: the adaptation of the methodological with the integration of factors of analysis such as slope, erodibility, erosivity and geology promoted a significant differentiation in the production of the final map for environmental fragility; the use of continuous ratings by the weighted average allowed for an analysis of the environmental fragility according to the scale of work used; the SPRING (GIS) software, combined with algorithms of map algebra, demonstrated effectiveness proved effective in the theoretical analysis of environmental fragility, confirming the possibility of applying the methodology in studies of environmental planning of watersheds.

Keywords: Vulnerability; geographic information system (GIS); land use.
\end{abstract}

\section{INTRODUÇÃO}

A influência antrópica no ambiente, inclusive em bacias hidrográficas, tem sido motivo frequente de preocupação na sociedade, o que tem levado ao aumento de pesquisas para qualificar e quantificar impactos da ocupação territorial. Nesse contexto, tem se tornado primordial o conhecimento 
prévio das características e da capacidade de uso do meio, ou mesmo durante os processos de desenvolvimento das atividades, com vistas ao aperfeiçoamento das tecnologias aplicadas.

A bacia hidrográfica, considerada como uma unidade de manejo ambiental, apresenta características intrínsecas, como relevo, tipo de solo e geologia que, em conjunto, convertem-se em um atributo denominado vulnerabilidade natural. Inserindo-se nessa unidade a ação humana, ou seja, introduzindo-se fatores externos de ocorrência não natural, é possível avaliar o nível de degradação que produzem. Surge assim a possibilidade de aplicação de estudos de fragilidade ambiental em bacias hidrográficas, constituindo-se numa importante ferramenta no planejamento ambiental estratégico.

Avaliações da fragilidade ambiental, baseadas em fatores como o solo, o potencial de erosão das chuvas, a declividade e a cobertura vegetal, são necessárias ao planejamento ambiental. O conhecimento dos níveis de fragilidade presentes em uma bacia hidrográfica, por meio da integração de diversas variáveis que interferem nas potencialidades dos recursos naturais, possibilita compreender a realidade e obter uma visão mais clara sobre quais são as opções mais adequadas para o uso da terra (SPÖRL, 2001).

Com isso, fica evidente que os estudos de fragilidade ambiental proporcionam melhor definição das diretrizes e ações a serem implantadas no espaço físico-territorial, servindo de base para o zoneamento ambiental e fornecendo subsídios à gestão do território (SPÖRL; ROSS, 2004).

Vashchenko et al. (2007) citam a importância desse tipo de estudo em trabalhos de zoneamento em unidades de conservação e em outros tipos de área protegidas.

Ross (1990) afirma que o planejamento não pode ser formulado a partir de uma leitura estática do ambiente, mas deve estar inserido no entendimento do processo de ocupação que norteia o desenvolvimento e a apropriação do território e de seus recursos. Desse modo, a necessidade de se executar o mapeamento da fragilidade ambiental em bacias hidrográficas vem ao encontro dos princípios de conservação dos recursos naturais e desenvolvimento sustentável.

No método proposto por Ross (1994), os procedimentos operacionais requerem uma base de dados que englobe informações referentes à declividade, tipo de solo e precipitação pluvial, além de dados acerca do uso da terra e cobertura vegetal, sendo que as informações são analisadas de forma integrada, gerando um mapa-síntese, em que é possível identificar os diferentes graus de fragilidade que o ambiente apresenta.

No entanto, a homogeneidade dos fatores inicialmente preconizada por esse método pode não ser sensível o suficiente às variações abordadas em determinados locais de estudo, de modo que não discrimine com exatidão os diferentes níveis de fragilidade que o ambiente tende a apresentar. Com essa perspectiva, a adaptação do método de Ross (1994) traz a possibilidade de tornar a metodologia aplicável a outras áreas de estudo, ampliando a diversidade de aplicação do método com resultados satisfatórios.

Diante do exposto, a hipótese do trabalho parte da possibilidade de se adaptar a metodologia de Ross (1994), a fim de determinar com eficiência os diferentes níveis de fragilidade ambiental em bacias hidrográficas. O objetivo do trabalho foi o de adaptar a proposta metodológica de Ross (1994) para novos procedimentos de determinação da fragilidade ambiental, tendo como estudo de caso a bacia hidrográfica do rio Dourados (MS).

\section{MATERIAL E MÉTODOS}

\section{Caracterização da área de estudo}

A bacia do rio Dourados localiza-se ao sul do estado de Mato Grosso do Sul (Figura 1), entre as coordenadas geográficas $21^{\circ} 56^{\prime}$ e $22^{\circ} 38^{\prime} \mathrm{S}$ e $53^{\circ} 59^{\prime}$ e $55^{\circ} 57^{\prime} \mathrm{O}$, abrangendo total ou parcialmente onze municípios. Situa-se na bacia do rio Ivinhema, que, por sua vez, se insere na bacia hidrográfica do rio Paraná (DANIEL et al., 2009).

No que se refere ao clima, a precipitação anual da região onde se encontra a bacia do rio Dourados varia de 1.200 a $1.600 \mathrm{~mm}$ (MATO GROSSO DO SUL, 1990). Arai et al. (2010), ao espacializarem a precipitação pluvial média anual na bacia hidrográfica do rio Dourados, do período de 1958 a 2007, verificaram que a precipitação na região de cabeceira da bacia atinge valores superiores a $1.750 \mathrm{~mm}$, decrescendo em direção à foz, onde se verificam precipitações médias anuais inferiores a $1.300 \mathrm{~mm}$.

Quanto à geologia, conforme o macrozoneamento geoambiental do estado de Mato Grosso do Sul (MATO GROSSO DO SUL, 1990), observa-se na área da bacia do rio Dourados a ocorrência de três 
litotipos distintos sobrepostos: JKsg - correspondente à Formação Serra Geral; Kc - correspondente à Formação Caiuá; e Qpp - correspondente à Formação Ponta Porã.

No que compete aos solos, de acordo com a Empresa Brasileira de Pesquisa Agropecuária (EMBRAPA) (2006), observam-se na área de estudo as seguintes classes pedológicas: Latossolos Latossolo Vermelho distrófico (LVd), Latossolo Vermelho aluminoférrico (LVaf), Latossolo Vermelho distroférrico (LVdf) e Latossolo Vermelho eutroférrico (LVef); Argissolos - Argissolo Vermelho alumínico (PVa); Gleissolos - Gleissolo Háplico eutrófico (GXbe); e Neossolos - Neossolo Quartzarênico órtico (RQo).

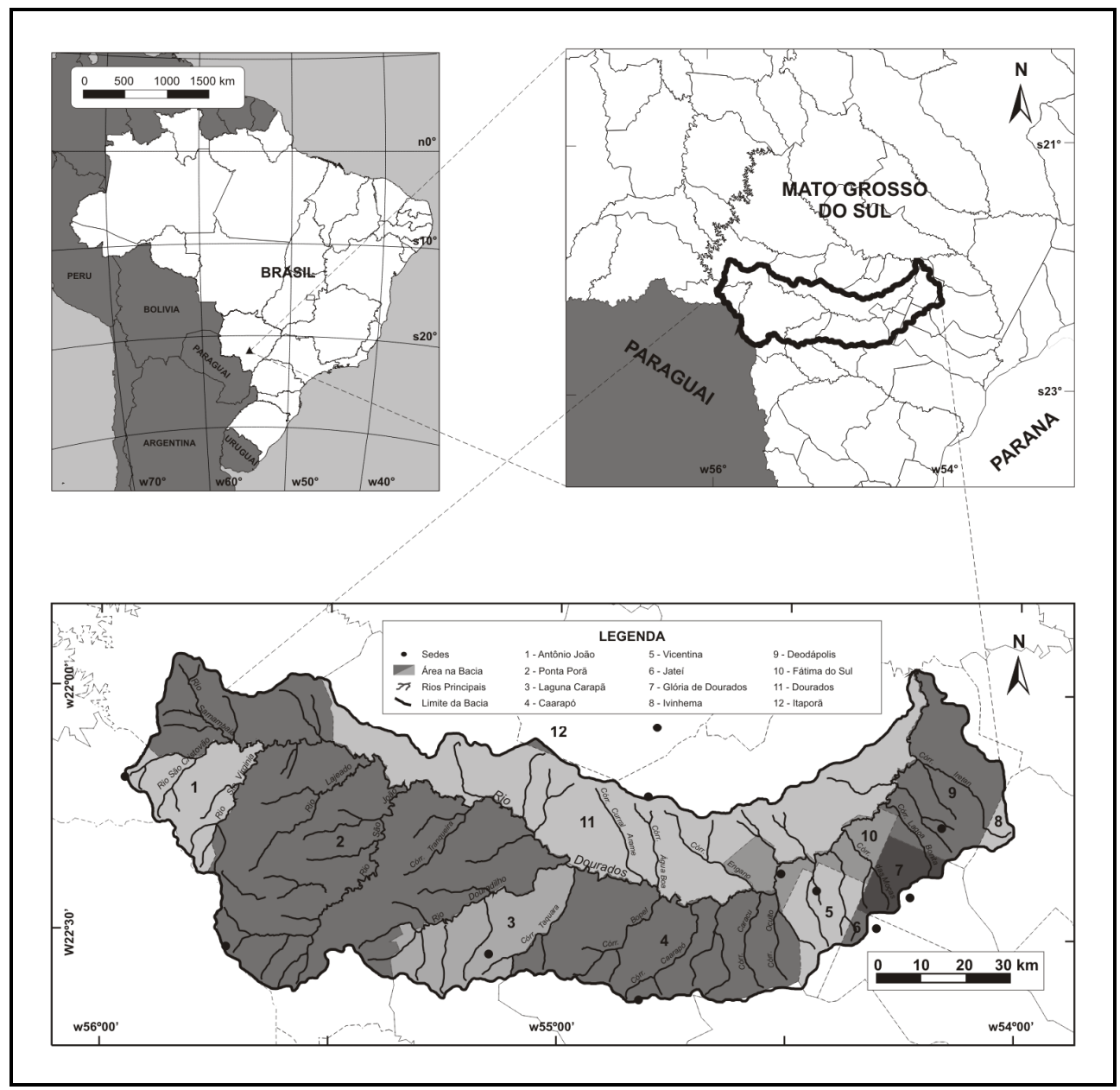

Figura 1. Localização da bacia do rio Dourados e municípios componentes.

Figure 1. Dourados river watershed localization and municipalities concerned.

\section{Processamento dos dados}

Todas as informações cartográficas necessárias foram preparadas em ambiente de geoprocessamento, com informações georreferenciadas, utilizando-se o software SPRING 4.3.3 (CÂMARA et al., 1996), sendo este de ampla utilização em atividades de análise espacial. Foram gerados os mapas de classes de declividade, erodibilidade dos solos, erosividade das chuvas, geologia e uso atual do solo, os quais geraram como produto final os mapas de fragilidade da área de estudo.

A metodologia proposta por Ross (1994), conhecida por "modelo de fragilidade potencial com apoio nas classes de declividade", utiliza as classes de solos, cobertura vegetal e pluviosidade aplicada na Equação Universal de Perda de Solo (EUPS). A hierarquia dos níveis de fragilidade é elaborada pelo referido autor de acordo com os diferentes estados de equilíbrio a que o ambiente está submetido. 
Os diferentes níveis de fragilidade são representados por códigos: muito fraca (1), fraca (2), média (3), forte (4) e muito forte (5). Essas categorias expressam especialmente a fragilidade do ambiente em relação aos processos ocasionados pelo escoamento superficial difuso e concentrado das águas pluviais.

Aplicando a álgebra de mapas no SPRING com a Linguagem Espacial para Geoprocessamento Algébrico (LEGAL) e operações de análise geográfica, foi possível obter os mapas de fragilidade ambiental. Como método de combinação de mapas (álgebra de campos), utilizou-se a classificação contínua, por meio da inferência média ponderada, em que um novo atributo quantitativo é associado ao atributo qualitativo, representado no modelo de grade numérica regular (MNT), criando uma representação de variação espacial contínua.

Por meio da grade regular numérica, o usuário define um espaçamento associando um valor de peso a cada ponto da grade. Desse modo, são gerados os modelos numéricos para diferentes representações. No caso deste trabalho, geraram-se grades numéricas para cada fator analisado: declividade, erodibilidade, erosividade, geologia e uso atual do solo (Figura 2).

Os dados referentes à declividade, erodibilidade, erosividade e geologia são considerados critérios que têm o objetivo de gerar os mapas de fragilidade ambiental. Porém, antes de serem processados com essa finalidade, esses critérios foram padronizados para a mesma escala de valores. O processo de padronização é o que permite que os mapas apresentem uniformidade (DE PAULA; SOUZA, 2007), permitindo comparações.

Observe-se que, além de utilizar os fatores determinados na metodologia de Ross (1994) (declividade e cobertura vegetal/uso da terra), adicionaram-se neste trabalho os fatores erodibilidade dos solos, erosividade das chuvas e dados de geologia, objetivando adaptar o método do autor citado, a fim de obter uma maior diferenciação quanto aos diferentes níveis de fragilidade do ambiente.

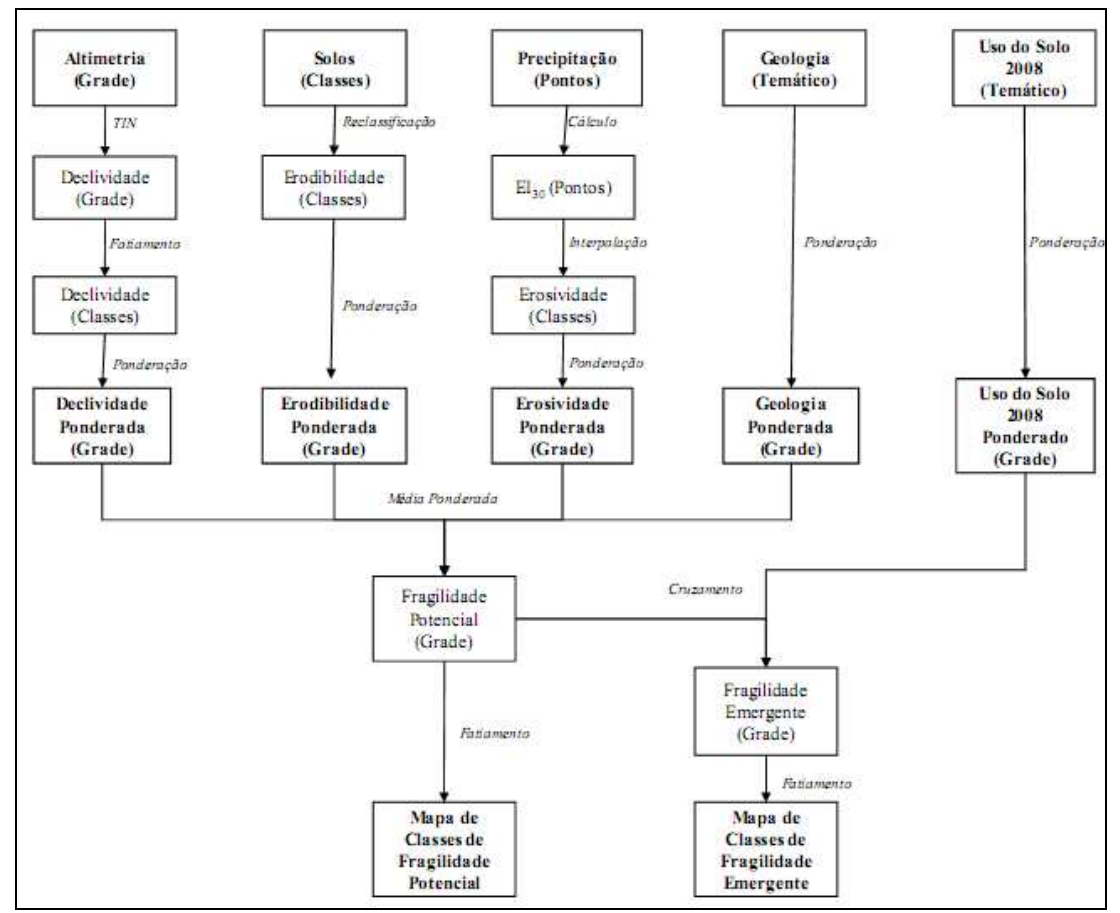

Figura 2. Fluxograma das atividades e produtos sobre a fragilidade ambiental.

Figure 2. Flowchart of activities and products related to environmental fragility.

Para cada produto intermediário (temático) foi gerada uma grade numérica, por meio de comandos de linguagem (LEGAL) que transforma um mapa temático em numérico e que posteriormente promove o fatiamento das classes do mapa. Essa opção foi desenvolvida exatamente para essas atividades de manipulação geográfica. A importância da ponderação consiste no fato de demonstrar a importância 
relativa de cada tema em uma determinada análise numérica, obedecendo a uma tabela de ponderação que associa um determinado valor (peso) a cada classe temática.

Cada fator (critério) foi ponderado de acordo com a sua importância na elaboração dos mapas de fragilidade ambiental. Os pesos foram determinados por atribuição direta com base em conhecimento empírico sobre o assunto, procurando ajustá-los (os pesos) ao número de classes, de forma a fornecer indicativo da contribuição do fator analisado para com o nível de fragilidade.

Para a variável declividade (Tabela 1), os pesos foram atribuídos com base nas classes de declividade propostas por Ross (1994), embora elas tenham sido adaptadas em virtude das condições reais da bacia (predomínio de classes baixas de declividade).

Tabela 1. Relação entre classes de declividade dos solos e classes de fragilidade.

Table 1. Relation between slope soil classes and fragility classes.

\begin{tabular}{lcc}
\hline Classes de declividade $(\boldsymbol{\%})$ & Classes de fragilidade & Fragilidade (peso) \\
\hline até 2 & Muito baixa & 0 \\
de 2 a 4 & Baixa & 2 \\
de 4 a 6 & Média & 3 \\
de 6 a 12 & Média forte & 5 \\
de 12 a 20 & Alta & 7 \\
de 20 a 30 & Muito alta & 8 \\
acima de 30 & Extremamente alta & 10 \\
\hline
\end{tabular}

Fonte: Adaptada de Ross (1994).

Para o fator erodibilidade (Tabela 2), a ponderação foi feita com base nos índices de erodibilidade estimados por Garbarino et al. (2004), ajustando-se a faixa de valores observada de acordo com o proposto por Freire e Pessoti (1974).

Tabela 2. Relação entre classes de erodibilidade dos solos e classes de fragilidade.

Table 2. Relation between erodibility soil classes of soils and fragility classes.

\begin{tabular}{lcc}
\hline $\begin{array}{l}\text { Classes de erodibilidade } \\
\left(\mathbf{t} \cdot \mathbf{h a} \mathbf{~} \mathbf{~} \cdot \mathbf{~ h a}^{\mathbf{- 1}} \mathbf{.} \mathbf{M J}^{\mathbf{- 1}} \mathbf{.} \mathbf{m m}^{\mathbf{- 1}}\right)\end{array}$ & Classes de fragilidade & Fragilidade (peso) \\
\hline Até 0,013 & Muito baixa & 1 \\
de 0,013 a 0,032 & Baixa & 3 \\
de 0,032 a 0,045 & Média & 5 \\
de 0,045 a 0,065 & Alta & 7 \\
acima de 0,065 & Muito alta & 10 \\
\hline
\end{tabular}

Fonte: Freire e Pessoti (1974).

Para o fator erosividade das chuvas (Tabela 3), a ponderação foi feita com base nas classes de erosividade propostas por Carvalho (2008), estimadas por meio da determinação do índice de erosividade $\left(\mathrm{EI}_{30}\right)$ para a bacia em estudo calculados por Arai et al. (2010). $\mathrm{O} \mathrm{EI}_{30}$ corresponde à energia cinética total da chuva (E) e à sua intensidade máxima em 30 minutos (I30), sendo um parâmetro pluviométrico útil na correlação das perdas de solo por erosão hídrica.

Tabela 3. Relação entre classes de erosividade e classes de fragilidade.

Table 3. Relation between erosivity classes and fragility classes.

\begin{tabular}{lcc}
\hline $\begin{array}{l}\text { Classes de erosividade } \\
\left.\text { (MJ } \mathbf{~ m m} \cdot \mathbf{h a}^{\mathbf{- 1}} \cdot \mathbf{h}^{\mathbf{- 1}} \mathbf{.} \mathbf{a n o}^{\mathbf{- 1}}\right)\end{array}$ & Classes de fragilidade & Fragilidade (peso) \\
\hline até 2.452 & Muito baixa & 1 \\
de 2.452 a 4.086 & Baixa & 3 \\
de 4.086 a 4.905 & Média & 5 \\
de 4.905 a 7.357 & Média forte & 6 \\
de 7.357 a 9.810 & Alta & 8 \\
acima de 9.810 & Muito alta & 10 \\
\hline
\end{tabular}

Fonte: Adaptada de Carvalho (2008). 
Já para o fator geologia (Tabela 4), foi considerada a descrição da escala de vulnerabilidade das litologias aos processos erosivos proposta por Crepani et al. (2001).

Tabela 4. Relação entre classes de geologia e classes de fragilidade.

Table 4. Relation between geology classes and fragility classes.

\begin{tabular}{lcc}
\hline Classes de geologia & Classes de fragilidade & Fragilidade (peso) \\
\hline Formação Serra Geral (JKsg) & Moderada & 3 \\
Formação Cauiá (Kc) & Média & 7 \\
Formação Ponta Porã (Qpp) & Alta & 8 \\
\hline Fonte: Adaptada de Crepani et al. $(2001)$. & &
\end{tabular}

Após o processo de ponderação, efetuou-se o cálculo da média aritmética, utilizando-se a linguagem LEGAL do SPRING, entre os valores da grade dos quatro temas considerados nas tabelas 1, 2, 3 e 4. A partir da média dos quatro fatores considerados, gerou-se a grade numérica que definiu o fatiamento da fragilidade potencial em cinco níveis: muito baixa, baixa, média, alta e muito alta, resultando na matriz correspondente à fragilidade potencial.

Ross (1994) propôs a metodologia para a análise da fragilidade ambiental, com o objetivo de estudar a relação entre o espaço geográfico integrada com a análise ambiental, tanto em ambiente em condições naturais quanto sob ação antrópica.

Com base na mesma ideia, realizou-se a ponderação do mapa de uso da terra, atribuindo-se pesos maiores a graus de proteção do solo menores e vice-versa. O mapa temático foi convertido em uma grade numérica, com valores correspondentes ao peso da classe nas distintas localizações (Tabela 5).

Tabela 5. Ponderação das classes de uso da terra.

Table 5. Land use classes ponderation.

\begin{tabular}{lc}
\hline Tipologias de uso do solo & Fragilidade (peso) \\
\hline Corpos d’água & 1 \\
Floresta & 2 \\
Cerrado & 3 \\
Complexo de vegetação & 3 \\
Eucalipto & 3 \\
Complexo urbano & 5 \\
Pastagem & 7 \\
Agricultura & 9 \\
\hline
\end{tabular}

Considera-se que as áreas correspondentes à agricultura, com cultivos de ciclo curto, como soja e milho, propiciam baixa proteção aos solos, tendo sido atribuídos os maiores pesos a essas classes. Já para a classe pastagem, considerou-se que é capaz de propiciar proteção média aos solos, em virtude de que se atribuiu um peso menor do que o da agricultura.

As áreas cuja cobertura correspondeu à floresta proporcionam proteção muito forte ao impacto das chuvas erosivas, motivo pelo qual foi atribuído o peso 2 (baixa fragilidade), enquanto que as áreas cobertas por cerrado ou complexo de vegetação conferem um grau mais baixo de proteção quando comparadas com as áreas de floresta.

A partir das grades referentes à fragilidade potencial e ponderação do uso da terra, foi possível calcular os valores de fragilidade emergente. Para fins de mapeamento, a grade final foi fatiada em cinco faixas, originando um novo mapa temático.

\section{RESULTADOS E DISCUSSÃO}

\section{Fragilidade potencial}

Na figura 3 observam-se as áreas de fragilidade potencial da bacia do rio Dourados, que é o estudo de caso proposto. Elaborou-se esse mapa a partir da relação entre a declividade, a erodibilidade 
dos solos, a erosividade das chuvas e a geologia, segundo a metodologia (Figura 2). Para tanto, as classes foram hierarquizadas em cinco níveis (Tabela 6).

Tabela 6. Quantificação da fragilidade potencial.

Table 6. Quantification of potential fragility classes.

\begin{tabular}{lcc}
\hline Classes de fragilidade potencial & Área (ha) & Área (\%) \\
\hline Muito baixa & 5.350 & 0,6 \\
Baixa & 626.044 & 67,7 \\
Média & 285.295 & 31,1 \\
Alta & 6.556 & 0,7 \\
Muito alta & 0 & 0 \\
\hline
\end{tabular}

Nota-se que as classes de fragilidade potencial observadas para a área de estudo foram: muito baixa $(0,6 \%)$, baixa $(67,7 \%)$, média $(31,1 \%)$ e alta $(0,7 \%)$. Ou seja, a bacia apresentou $98,8 \%$ correspondentes às classes fragilidade potencial baixa e média, sem expressão da classe muito alta.

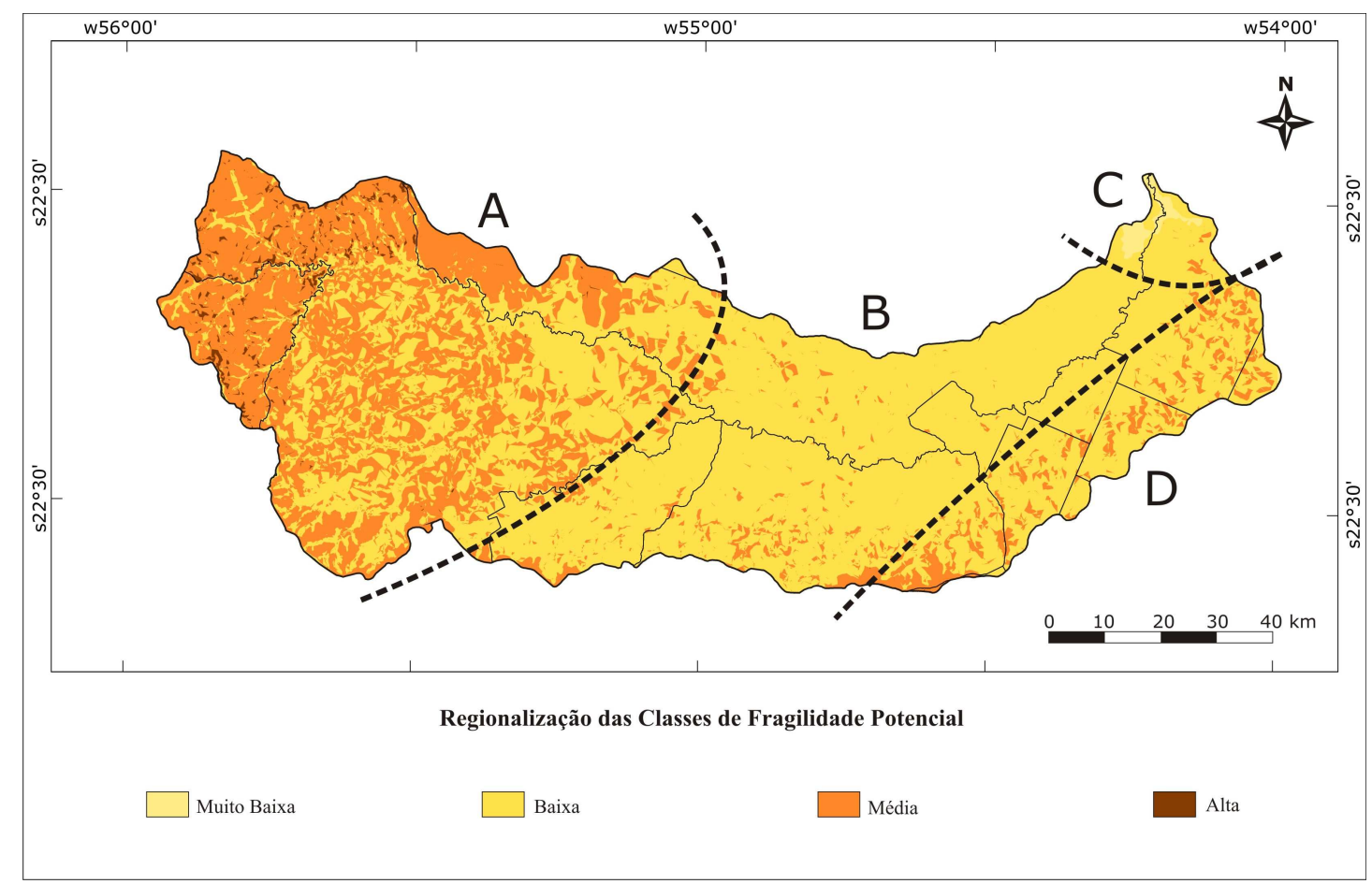

Figura 3. Classes de fragilidade potencial em zonas A, B, C e D.

Figure 3. Potential fragility classes for the study area in zones A, B, C e D.

Observa-se ainda, na figura 3, tendência à regionalização das classes de fragilidade potencial, com as áreas em que houve expressão de média e alta fragilidade potencial correspondendo às áreas em que foram registrados os maiores índices de erosividade e declividade (Zona A). Essa zona abrange a região de cabeceira de drenagem da bacia, distribuindo-se em sua maior parte pelos municípios de Antonio João e Ponta Porã, uma vez que a referida região situa-se no divisor de bacias (Figura 1).

A declividade é um dos fatores que influencia fortemente nos processos de erosão, sobretudo na erosão hídrica do solo, pois, à medida que ela aumenta, aumentam o volume e a velocidade da enxurrada e diminui a infiltração de água no solo (COGO et al., 2003). Sendo assim, áreas com declividades acentuadas tendem a apresentar maiores níveis de fragilidade potencial.

A classe de fragilidade potencial definida como sendo alta ocorreu apenas em $0,7 \%$ da área. Santos (2005) constatou que essas classes estão ligadas a relevos mais inclinados, acima de $20 \%$, e 
associados a solos com menor profundidade e menor capacidade de drenagem. Donha et al. (2006) também observaram classes de fragilidade potencial alta associadas à classe de declividade alta.

$\mathrm{Na}$ Zona $\mathrm{B}$, correspondente à região onde se localiza a sede do município de Dourados (Figura 1), predominaram classes de fragilidade potencial baixa, indicando que há uma relação entre a ocorrência do Latossolo Vermelho distroférrico (LVdf) com a predominância das classes de declividade muito baixa e baixa.

Já na Zona $\mathrm{C}$ ocorreram classes de fragilidade muito baixa. Observa-se nessa região a predominância de solos de várzea, representados pelo Gleissolo Háplico Eutrófico-GXbe, sendo que esses solos normalmente encontram-se permanente ou periodicamente saturados por água (EMBRAPA, 2006).

Na Zona D observou-se a expressão da classe de fragilidade média. Os arenitos da Formação Caiuá dessa região encontram-se associados a um relevo mais acidentado, apresentando vales mais profundos e com a ocorrência de solos friáveis de textura mais arenosa. Assim, o relevo mais íngreme dessa região facilita o aumento da velocidade do fluxo do escorrimento de água das chuvas, favorecendo a erosão hídrica.

A Zona D compreende os municípios de Vicentina, Glória de Dourados e Deodápolis, e apresentou médio potencial de fragilidade, visto que tem como atividade principal a pecuária, condição que oferece baixa proteção aos solos, estando aliada à ocorrência predominante do Latossolo Vermelho distrófico ( $\mathrm{LVd}$ ) e do Argissolo Vermelho (PV), além de pequenas manchas correspondentes aos Neossolos Quartzarênicos (RQo). Esses solos apresentam alta susceptibilidade à erosão, especialmente em forma de ravinas e voçorocas. Em Glória de Dourados, onde predominam as duas primeiras classes de solos, é comum o assoreamento de cursos d'água (LIMA, 2006).

Portanto, nota-se que as classes de fragilidade potencial compreendidas entre muita baixa e média representam $99,4 \%$ da área total da bacia hidrográfica, praticamente sua totalidade. Esse predomínio ocorreu em função de declividades pouco acentuadas em quase toda a região. As declividades de até $12 \%$ estão presentes em $95,5 \%$ da área total.

Convém ainda destacar que, a partir da análise conjunta dos dados considerados determinantes no mapeamento da fragilidade ambiental, foi possível perceber a interação que há entre os fatores utilizados como critérios na determinação da fragilidade ambiental. Ao considerarmos, por exemplo, a Zona D da figura 3, é possível observar a interação que existe entre a ocorrência do Latossolo Vermelho distrófico (LVd4), oriundo dos arenitos da Formação Caiuá, com o relevo mais íngreme dessa região, fatores estes que, em conjunto, favoreceram a ocorrência de áreas mais susceptíveis à erosão, conferindo classes de média fragilidade ambiental à Zona D.

Essa classe de solo, particularmente o LVd20, também apresentou ocorrência na Zona A, coincidindo com as áreas em que foram observadas as mais altas classes de fragilidade. Mais uma vez ficou clara a importância da interação do fator declividade com as classes de maior fragilidade ambiental.

Destacou-se também, na Zona A, a influência da erosividade na elevação dos níveis de fragilidade, pois é uma região que apresenta maior precipitação pluviométrica e a ocorrência da classe de solo LVd20, que se caracteriza por um alto nível de erodibilidade, segundo estimativas do modelo matemático aplicado (GARBARINO et al., 2004). Assim, a interação desses fatores juntamente com a ocorrência da Formação Ponta Porã, cujos arenitos apresentam alto nível de fragilidade (CREPANI et al., 2001), favoreceram a expressão das classes de fragilidade média e alta na Zona A.

Observou-se durante a elaboração dos mapas que a inserção do fator geologia proporciona uma significativa diferenciação nos níveis de fragilidade ambiental, visto que reforça o fator erodibilidade dos solos, o qual é intimamente relacionado ao material de origem. Assim, uma forma de destacar o efeito da erodibilidade dos solos na determinação da fragilidade ambiental é incluir o fator geologia.

Os resultados permitem afirmar que a bacia hidrográfica do rio Dourados apresenta-se em relativo equilíbrio ambiental no que se refere às variáveis estudadas, em função da predominância de baixas declividades e da maior cobertura por Latossolos, que são profundos e bem drenados, garantindo uma estabilidade natural.

Porém, convém destacar que a preponderância de classes de fragilidade potencial baixa e média não implica necessariamente a permanência futura desses índices, já que isso depende da influência da ação antrópica na área de estudo. 


\section{Fragilidade emergente}

Verifica-se na figura 4 que a expressão das classes média e alta de fragilidade emergente concentrou-se na região de cabeceira da bacia e nas áreas próximas ao município de Ponta Porã. De fato, essa foi a região que também apresentou classes de fragilidade potencial média e alta.

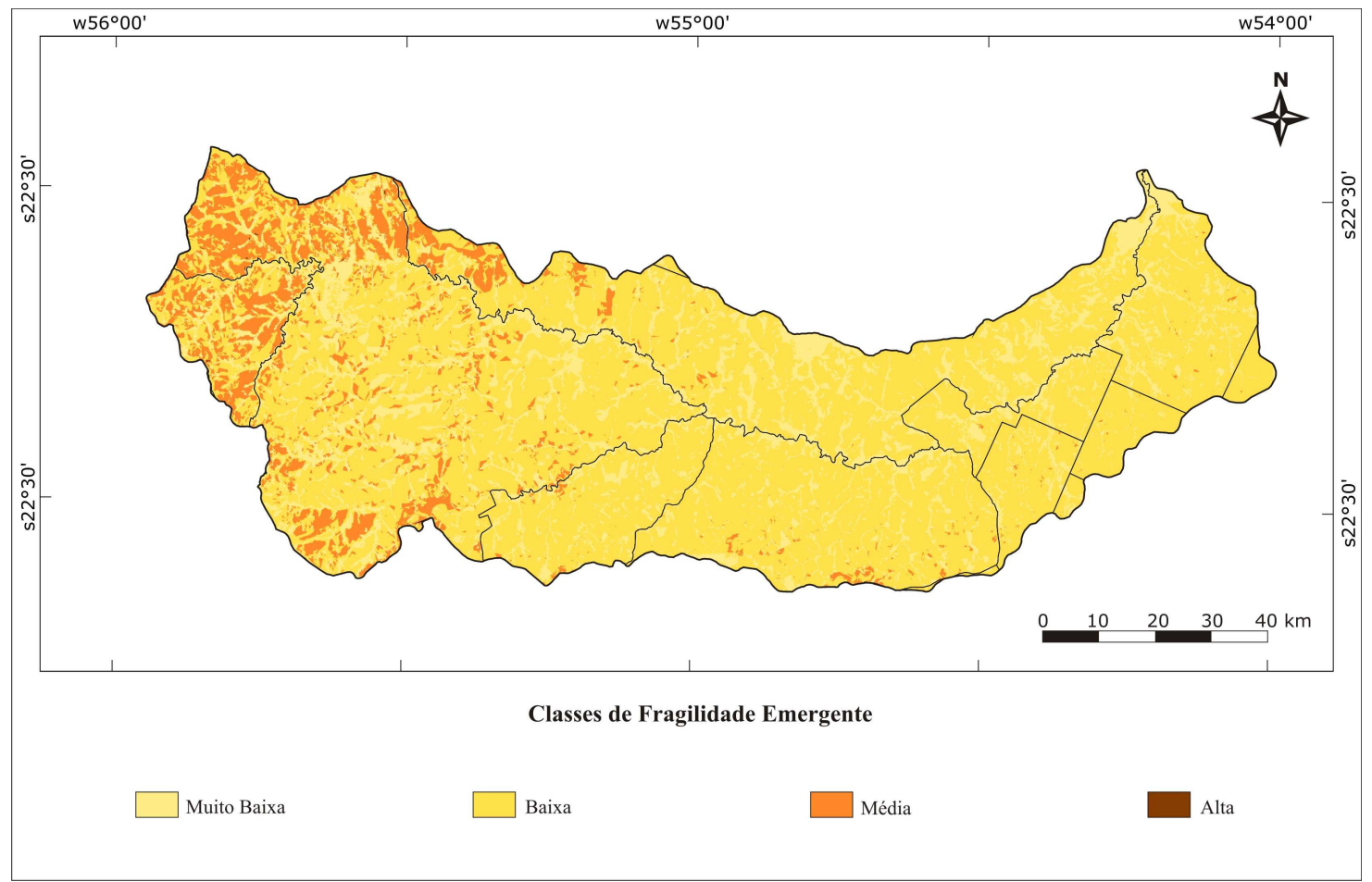

Figura 4. Classes de fragilidade emergente.

Figure 4. Emerging fragility classes.

Com relação às classes de fragilidade emergente encontradas, destaca-se a baixa, correspondendo a $70,7 \%$ da área total, e a muito baixa, com $20,1 \%$ da área; em seguida tem-se a classe de fragilidade média, representando $9,2 \%$, e a classe alta, com $0,02 \%$. Não houve ocorrência da classe muito alta (Tabela 7).

Tabela 7. Quantificação da fragilidade emergente.

Table 7. Quantification of emerging fragility classes.

\begin{tabular}{lcc}
\hline Classes de fragilidade emergente & Área (ha) & Área (\%) \\
\hline Muito baixa & 184.778 & 20,1 \\
Baixa & 651.356 & 70,7 \\
Média & 84.659 & 9,2 \\
Alta & 153 & 0,02 \\
Muito alta & 0 & 0 \\
\hline
\end{tabular}

As classes de fragilidade emergente que apresentaram maior expressão foram as classes muito baixa e baixa. Juntas, elas abrangeram $90,8 \%$ do total da área da bacia, tendo compreendido, inclusive, grande proporção das áreas destinadas às práticas agropecuárias, já que estas perfazem a maior parte das atividades desenvolvidas.

Nesse sentido, ao considerar a aplicação de atividades agrícolas tecnologicamente adequadas, por exemplo, na forma de plantio direto associado a um sistema de controle de escoamento superficial, como o terraceamento, a adequação das estradas rurais em bases conservacionistas e o plantio em nível, é possível promover a redução da fragilidade potencial na bacia, em função do efeito dos fatores cobertura do solo e gerenciamento das enxurradas. 
Porém, em estudos de planejamento territorial, a fragilidade potencial apresenta uma importância maior, já que na fragilidade emergente não existe uma constância no tipo de cobertura do solo, sendo esta frequentemente variável.

\section{CONCLUSÕES}

- A integração dos fatores de análise declividade, erodibilidade dos solos, erosividade das chuvas e geologia à metodologia proposta por Ross (1994) promoveu diferenciação significativa na elaboração do mapa final de fragilidade potencial.

- A utilização da classificação contínua por meio da média ponderada permitiu uma análise da fragilidade ambiental condizente com a escala de trabalho utilizada.

- Os Sistemas de Informações Geográficas, por meio do SPRING e da álgebra de mapas, demonstraram eficácia na análise teórica da fragilidade ambiental, atestando a possibilidade de aplicação da metodologia em estudos de planejamento ambiental em bacias hidrográficas.

- O que é importante enfatizar é o fato de que, quanto maior for a incorporação de novos fatores na metodologia de análise, desde que eles estejam relacionados com a determinação da fragilidade ambiental, mais condizentes com a realidade local serão os resultados obtidos. Dessa forma, torna-se fundamental a avaliação e estudos sobre a incorporação de novos fatores à metodologia original, além daqueles acrescentados neste trabalho. A maleabilidade da metodologia possibilita ao analista ou ao planejador ambiental adaptar novos fatores segundo os objetivos almejados para os mapas de fragilidade ambiental.

- Atestamos a hipótese do trabalho, visto que observamos a possibilidade de se adaptar o método de Ross (1994) à determinação da fragilidade ambiental em bacias hidrográficas.

\section{AGRADECIMENTOS}

À Fundação de Apoio ao Desenvolvimento do Ensino, Ciência e Tecnologia do Estado de Mato Grosso do Sul (FUNDECT), pelo apoio financeiro.

\section{REFERÊNCIAS}

ARAI, F. K.; GONÇALVES, G. G. G.; PEREIRA, S. B.; COMUNELlO, E.; VITORINO, A. C. T.; DANIEL, O. Espacialização da precipitação e erosividade na bacia hidrográfica do rio Dourados, MS. Engenharia Agrícola, Jaboticabal, v. 30, n. 5, p. 922 - 931, 2010.

CÂMARA, G.; SOUZA, R. C. M.; FREITAS, U. M.; GARRIDO, J. C. P. SPRING: integrating remote sensing and GIS by object-oriented data modelling. Computers \& Graphics, v. 20, p. 395 - 403, 1996.

CARVALHO, N. O. Hidrossedimentologia prática. 2. ed. Rio de Janeiro: Editora Interciência, 2008. 600 p.

COGO, N. P; LEVIEN, R; SCHWARZ, R. A. Perdas de solo e água por erosão hídrica influenciadas por métodos de preparo, classes de declive e níveis de fertilidade do solo. Revista Brasileira de Ciência do Solo, Viçosa, v. 27, n. 4, p. 743 - 753, 2003.

CREPANI, E.; MEDEIROS, J. S. de; HERNANDEZ, P.; FLORENZANO, T. G.; DUARTE, V.; BARBOSA, C. C. F. Sensoriamento remoto e geoprocessamento aplicados ao zoneamento ecológicoeconômico e ao ordenamento territorial. São José dos Campos: SAE/INPE, 2001. 103 p.

DANIEL, O.; VITORINO, A. C. T.; VERONESI, C. O.; QUEIROZ, L. S.; GELAIN, E. Uso da terra na Bacia do Rio Dourados, MS, por meio de imagens LANDSAT. In: CONGRESO ARGENTINO DE INGENIERÍA RURAL Y II DEL MERCOSUR, 10., 2009, Rosario. Anais do... Rosário: UNR, 2009. p. $1833-1838$.

DE PAULA, E. M. S.; SOUZA, M. J. N. Lógica Fuzzy como técnica de apoio ao zoneamento ambiental. In: SIMPÓSIO BRASILEIRO DE SENSORIAMENTO REMOTO, 13., 2007, Florianópolis. Anais do... Florianópolis: INPE, 2007. p. 2979 - 2984. 
DONHA, A. G.; SOUZA, L. C. de.; SUGAMOSTO, M. L. Determinação da fragilidade ambiental utilizando técnicas de suporte à decisão e SIG. Revista Brasileira de Engenharia Agrícola e Ambiental, v. 10, n. 1, p. 175 - 181, 2006.

EMPRESA BRASILEIRA DE PESQUISA AGROPECUÁRIA (EMBRAPA). Centro Nacional de Pesquisa de Solos. Sistema brasileiro de classificação de solos. 2. ed. Rio de Janeiro: Embrapa Solos, 2006. $306 \mathrm{p}$.

FREIRE O.; PESSOTTI, J. E. S. Erodibilidade de alguns solos de Piracicaba, SP. In: ENCONTRO NACIONAL DE PESQUISA SOBRE CONSERVAÇÃO DO SOLO, 4., 1971. Anais do... Passo Fundo: EMBRAPA/CNPT, 1978. p. 481.

GARBARINO, G.; CELI, L.; STANCHI, S.; DANIEL, O.; VITORINO, A. C. T.; ZANINI, E. Valutazione dell'erodibilità dei suoli di un bacino tropicale (Mato Grosso do Sul, Brasile) tramite sistemi informativi geografici. In: CONVEGNO ANNUALE SUOLO E DINAMICHE AMBIENTALI, 3., 2004, Anais do..., 2004. p. 279 - 284.

LIMA, P. A. de. Transformações da paisagem nos municípios de Fátima do Sul, Glória de Dourados e Deodápolis: região meridional de Mato Grosso do Sul. 172 f. Tese (Doutorado em Geografia) Universidade Estadual Paulista, Rio Claro, 2006.

MATO GROSSO DO SUL. Secretaria de Planejamento e Coordenação Geral, Fundação Instituto de Apoio ao Planejamento do Estado. Macrozoneamento geoambiental do estado de Mato Grosso do Sul. Campo Grande, 1990.

ROSS, J. L. S. Geomorfologia, ambiente e planejamento. São Paulo: Contexto, 1990. 88 p.

. Análise empírica da fragilidade dos ambientes naturais e antropizados. Revista do Departamento de Geografia, São Paulo, n. 8, p. 24 - 30, 1994.

SANTOS, E. Mapeamento da fragilidade ambiental da bacia hidrográfica do rio Jirau, município de Dois Vizinhos, Paraná. 141 f. Dissertação (Mestrado em Geografia) - Universidade Federal do Paraná, Curitiba, 2005.

SPÖRL, C. Análise da fragilidade ambiental relevo-solo com aplicação de três modelos alternativos nas altas bacias do Rio Jaguari-Mirim, Ribeirão do Quartel e Ribeirão da Prata. 159 f. Dissertação (Mestrado em Geografia Física) - Universidade de São Paulo, São Paulo, 2001.

SPÖRL, C.; ROSS, J. L. S. Análise comparativa da fragilidade ambiental com aplicação de três modelos. GEOUSP: Espaço e Tempo, São Paulo, n. 15, p. 39 - 49, 2004.

VASHCHENKO, Y.; FAVARETTO, N.; BIONDI, D. Fragilidade ambiental nos picos Camacuã, Camapuã e Tucum, Campina Grande do Sul, PR. Floresta, Curitiba, v. 37, n. 2, p. 201 - 215, 2007. 